\title{
Adenoviral-mediated correction of methylmalonyl-CoA mutase deficiency in murine fibroblasts and human hepatocytes Randy J Chandler ${ }^{1,2}$, Matthew S Tsai ${ }^{1,3}$, Kenneth Dorko ${ }^{4}$, Jennifer Sloan ${ }^{1}$, Mark Korson ${ }^{5}$, Richard Freeman ${ }^{6}$, Stephen Strom ${ }^{4}$ and Charles P Venditti*1
}

Address: ${ }^{1}$ National Human Genome Research Institute, National Institutes of Health, Bethesda, MD 20892, USA, ${ }^{2}$ Department of Biochemistry and Molecular Biology, Georgetown University, Washington, DC 20057, USA, ${ }^{3}$ Miller School of Medicine, University of Miami, Miami, FL 33136, USA, ${ }^{4}$ Department of Pathology, University of Pittsburgh School of Medicine, Pittsburgh, PA 15261, USA, ${ }^{5}$ Division of Metabolism, Tufts

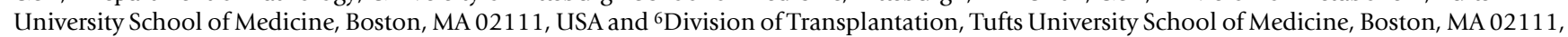
USA

Email: Randy J Chandler - rchandler@mail.nih.gov; Matthew S Tsai - matt.tsai@gmail.com; Kenneth Dorko - dorkok@pitt.edu; Jennifer Sloan - jsloan@mail.nih.gov; Mark Korson - mkorson@tufts-nemc.org; Richard Freeman - RFreeman@tufts-nemc.org; Stephen Strom - strom@pitt.edu; Charles P Venditti* - venditti@mail.nih.gov

* Corresponding author

Published: 30 April 2007

BMC Medical Genetics 2007, 8:24 doi:10.1 186/I47/-2350-8-24
Received: 18 January 2007

Accepted: 30 April 2007

This article is available from: http://www.biomedcentral.com/I47/-2350/8/24

(C) 2007 Chandler et al; licensee BioMed Central Ltd.

This is an Open Access article distributed under the terms of the Creative Commons Attribution License (http://creativecommons.org/licenses/by/2.0), which permits unrestricted use, distribution, and reproduction in any medium, provided the original work is properly cited.

\begin{abstract}
Background: Methylmalonic acidemia (MMA), a common organic aciduria, is caused by deficiency of the mitochondrial localized, 5'deoxyadenosylcobalamin dependent enzyme, methylmalonyl-CoA mutase (MUT). Liver transplantation in the absence of gross hepatic dysfunction provides supportive therapy and metabolic stability in severely affected patients, which invites the concept of using cell and gene delivery as future treatments for this condition.
\end{abstract}

Methods: To assess the effectiveness of gene delivery to restore the defective metabolism in this disorder, adenoviral correction experiments were performed using murine Mut embryonic fibroblasts and primary human methylmalonyl-CoA mutase deficient hepatocytes derived from a patient who harbored two early truncating mutations, E224X and R228X, in the MUT gene. Enzymatic and expression studies were used to assess the extent of functional correction.

Results: Primary hepatocytes, isolated from the native liver after removal subsequent to a combined liver-kidney transplantation procedure, or Mut murine fibroblasts were infected with a second generation recombinant adenoviral vector that expressed the murine methylmalonyl-CoA mutase as well as eGFP from distinct promoters. After transduction, $[\mathrm{I}-14 \mathrm{C}]$ propionate macromolecular incorporation studies and Western analysis demonstrated complete correction of the enzymatic defect in both cell types. Viral reconstitution of enzymatic expression in the human methylmalonyl-CoA mutase deficient hepatocytes exceeded that seen in fibroblasts or control hepatocytes.

Conclusion: These experiments provide proof of principle for viral correction in methylmalonic acidemia and suggest that hepatocyte-directed gene delivery will be an effective therapeutic treatment strategy in both murine models and in human patients. Primary hepatocytes from a liver that was unsuitable for transplantation provided an important resource for these studies. 


\section{Background}

Methylmalonic acidemia (MMA) is a common organic aciduria characterized by elevated levels of methylmalonic acid in the fluids and tissues of the body [1]. Affected patients have a well-recognized clinical phenotype $[2,3]$, characterized by acute metabolic decompensation, and a guarded long-term prognosis [4-7]. The metabolic disorder commonly results from mutations in the methylmalonyl-CoA mutase (MUT) gene $[8,9]$. This enzyme catalyzes the formation of succinyl-CoA from Lmethylmalonyl-CoA, a critical intermediate step in the conversion of propionyl-CoA to succinyl-CoA. Two enzymatic phenotypes of mut methylmalonic acidemia are recognized. Fibroblasts from $m u t^{\circ}$ patients have no detectable or residual enzyme activity in their fibroblasts [10] while those from mut patients have enzyme activity that is markedly reduced but typically cobalamin-responsive in vitro $[11,12]$.

The precise etiology of the complications seen in methylmalonic acidemia are uncertain, and even patients under treatment are at risk for intermittent metabolic decompensation, pancreatitis[13], infarction of the basal ganglia[14,15], and renal failure[7,16]. The main treatment of vitamin B-12 non-responsive methylmalonic acidemia includes nutritional management and alkali replacement $[2,3]$ as well as carnitine supplementation[17]. Despite restriction of dietary precursors, many patients exhibit metabolic fragility that can be life-threatening. Some individuals have undergone liver and combined liver-kidney transplantion to eliminate the metabolic instability that is characteristic of the condition [18-21]. Liver and liver-kidney transplant recipients do not experience life-threatening ketoacidotic attacks, but remain at risk for renal disease [20] and infarction of the basal ganglia[21]. While the timing, indications, efficacy and outcomes of patients undergoing these procedures have not been fully defined, the metabolic stability conferred after liver transplantation indicates that the liver plays a critical role in methylmalonyl-CoA metabolism. This suggests that hepatocytedirected viral or cell therapies may provide viable alternatives to liver transplantation in MMA patients who cannot find a donor organ or for whom the risk of transplantation is prohibitive. Hepatocyte transplantation has been used clinically and has been shown to provide partial or complete correction of several liver based metabolic diseases [22] and may represent a viable alternative to transplantation in affected MMA patients.

Previous attempts to use viral mediated gene delivery to correct the metabolic defect in $m u t^{0}$ primary fibroblasts were inefficient and required multiple cycles of retroviral infection and selection to restore propionate flux[23]. In this report, we describe the generation of a versatile adenoviral vector that co-expresses the methylmalonyl-CoA mutase gene and an eGFP reporter from independent promoters. The virus efficiently restored propionate metabolism in methylmalonyl-CoA mutase deficient murine fibroblasts as well as human hepatocytes derived from a patient with $m u t^{0}$ methylmalonic acidemia and was easily tracked by in vivo fluorescence after direct intraheptic injection in mice. The results demonstrate the efficacy of viral correction of the enzymatic defect in varied cell types from mouse and man and provide evidence for viral based gene delivery approaches to treat methylmalonic acidemia. The extent of correction achieved in primary $m u t^{0}$ hepatocytes was greater than that seen in fibroblasts or control hepatocytes and suggests that hepatocytedirected gene delivery will be an effective therapeutic strategy in both murine models and in human patients.

\section{Methods \\ Patient medical history}

Human hepatocytes used in viral correction experiments were derived from the discarded liver of a 5 year old boy with $m u t^{0}$ class methylmalonic acidemia undergoing a combined renal and hepatic transplant procedure. The patient initially presented with hyperammonemia and metabolic crisis in the presence of extreme methylmalonic acid elevations on the second day of life. Complementation and $[1-14 \mathrm{C}]$ propionate incorporation studies on skin fibroblasts indicated a $m u t^{0}$ lesion. Subsequent sequencing of the MUT gene revealed two early nonsense mutations, E224X and R228X[9]. At the age of five, the patient underwent a combined liver kidney transplant from a deceased donor in which the whole organ liver and left kidney allografts were implanted in one procedure.

\section{Cell lines}

Mut and wild-type murine embryonic fibroblasts have been described[24,25] and were isolated after a timed mating between mice carrying a targeted deletion of the Mut gene.

Hepatocytes from the affected patient were isolated after the liver was removed as part of elective combined liverkidney transplantation. The liver was considered a discarded surgical specimen because it was not suitable for transplantation and was donated by the family for research use. Patient studies were conducted in compliance with the Helsinki Declaration and were approved by the National Human Genome Research Institute Institutional Review Board as part of NIH study 04-HG-0127 "Clinical and Basic Investigations of Methylmalonic Acidemia and Related Disorders" after informed consent was obtained. Hepatocyte isolation from resected liver specimens was approved by the University of Pittsburg Institutional Review Board (IRB Number 0411142). Immediately upon surgical removal of the native liver the organ was flushed with ice-cold University of Wisconsin 
solution and shipped on wet ice to the University of Pittsburgh cell isolation facility established as part of the NIHfunded Liver Tissue Procurement and Distribution System. Hepatocytes were isolated from as described by Strom et al. [26,27], with some minor changes described here. Briefly, cells were isolated from the entire liver by a 3 -step collagenase perfusion protocol. Catheters were sewn in place into the 3 of the large hepatic veins and the liver was placed in a sterile plastic bag, and connected to a pump that delivered perfusate at approximately $80 \mathrm{mls} /$ minute/catheter. The liver was sequentially perfused with 1 liter of calcium and magnesium-free HBSS (Cambrex, Walkersville, MD) containing EGTA (1 mM), 1 liter of HBSS without EGTA. Finally, 1 liter of Minimum Essential Medium Eagle (EMEM, Cambrex, Walkersville, MD) containing $250 \mathrm{mg}$ collagenase (Type XI, Sigma, St. Louis, $\mathrm{MO}$ ) and $50 \mathrm{mg}$ of DNAase (Sigma, St. Louis, MO) was recirculated until the tissue was digested (approximately 29 minutes). Following digestion, tissue was placed in a sterile beaker, covered in ice-cold buffer EMEM and thoroughly chopped with a sterile scissors. Buffer and cells were decanted through sterile gauze covered funnels. Hepatocytes were enriched relative to nonparenchymal cells by 3 consecutive centrifugation steps at $75 \times \mathrm{g}$ for 5 minutes each. The final cell pellet was resuspended in hepatocyte maintenance medium (HMM, Cambrex, Walkersville, MD) and the viability was assessed by trypan blue exclusion. Visual inspection revealed greater than 95\% parenchymal hepatocytes that were then plated on six well plates as described [26] and allowed to attach for $4 \mathrm{hr}$, washed twice in serum-free media to remove dead and unattached cells and maintained thereafter by daily changes with serum-free HMM media. Control hepatocytes were isolated from a second donor, a 63 year old Male, not suspected to have primary liver disease or methylmalonic acidemia.

\section{Adenoviral vector construction and production}

A murine methylmalonyl-CoA mutase cDNA that contained a consensus Kozak sequence and minimal untranslated regions was isolated from C57/BL6 liver RNA after RT-PCR, sequenced and tested for enzymatic activity after expression in yeast using the succinate-thiokinase linked assay[25]. The gene was then cloned as an EcoRI fragment into the polylinker of pShuttle between the CMV promoter and the Sv40 polyadenylation signal (ViraQuest Inc., North Liberty, IA). This E1 shuttle expressing Mut from the CMV promoter was then used in the RAPAd ${ }^{\circledR}$ (U.S. Patent \#6,830,920) adenovirus construction system with an RSV eGFP expressing E3 backbone[28]. The dualexpressing virus was derived by recombination after cotransfection of the E1 shuttle and backbone into HEK293 cells. 7-10 days after the appearance of viral foci, the plates were harvested and amplified, and then virus particles were isolated by two rounds of $\mathrm{CsCl}$ gradients and dialyzed against storage buffer (ViraQuest Inc., North Liberty, IA). Vector genomes and plaque forming units (PFU) were measured in the final adenoviral preparations. Animal studies were reviewed and approved by the National Human Genome Research Institute Animal User Committee. The cell culture correction experiments used virus at a multiplicity of infection (MOI) of 1000. Direct intrahepatic injections of $1.0 \times 10^{10}$ particles $\left(3.3 \times 10^{8} \mathrm{PFU}\right)$ of the adenovirus in mixed background (C57Bl6xSv129Ev) neonatal mice were accomplished using a 32 gauge Hamilton syringe. The animals were sacrificed 4 days later for dissection and analysis of eGFP expression.

\section{Incorporation studies}

Methylmalonyl-CoA mutase activity was determined by measuring $\left[1-{ }^{14} \mathrm{C}\right]$ propionate incorporation into macromolecules as described[29]. All propionate incorporation assays were performed in triplicate. $\left[1-{ }^{14} \mathrm{C}\right]$ Sodium propionate was purchased (Perkin Elmer, Boston, MA) as a custom preparation at a specific activity of $55.0 \mathrm{mCi} / \mathrm{mmol}$ $(2 \mathrm{mCi} / \mathrm{ml})$.

\section{Western blotting}

Whole cell extracts from the cell lines were analyzed by immunoblotting and probed with affinity purified, rabbit polyclonal antisera raised against the murine methylmalonyl-CoA mutase enzyme or beta-actin (Abcam, Cambridge, MA). The anti-mutase antibody was used at a dilution of 1:750, and beta-actin was used at 1:5,000. Goat anti-rabbit (Chemicon, Temecula, CA) was used as a secondary antibody at dilution of 1:10,000 with chemiluminescent detection (Pierce Biotechnology, Rockford, IL). Recombinant murine methylmalonyl-CoA mutase enzyme was used as a positive control in Western blot analysis experiments. Human liver extracts were prepared from an anonymous liver donor not known to have methylmalonic acidemia or the $m u t^{0}$ patient described above.

\section{Results}

\section{Bifunctional adenoviral construction}

Transfection and recombination in HEK293 cells using the RAPAd ${ }^{\circledR}$ adenovirus method was used to produce replication deficient adenovirus particles that express the murine methylmalonyl-CoA mutase gene in the E1 region and eGFP from the E3 region[28]. The resulting replication deficient adenovirus expresses both genes from two independent promoters, Mut from the CMV and eGFP from the RSV (Figure 1). The virus was expanded, amplified and concentrated to an infectious titer of $1.2 \times 10^{12}$ particles/ml (corresponding to $4.0 \times 10^{10} \mathrm{PFU} / \mathrm{ml}$ ), indicating its stability during growth and replication. The strong viral promoters were selected to promote highlevel expression in a wide spectrum of tissues types, in vivo and in vitro. 


\section{Schematic overview of the helper-dependent advenovirus that expresses methylmalonyl-CoA mutase and eGFP.}

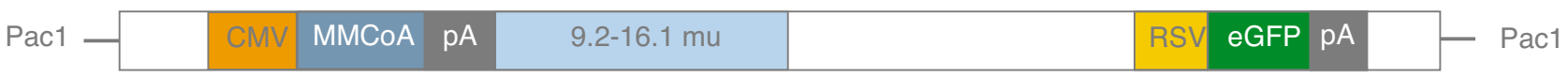

\section{Figure I}

Schematic of adenovirus. An overview of the recombination strategy used to construct the EI, E3 replaced adenovirus. CMV cytomegalovirus promoter. MMCoA - murine methylmalonyICoA mutase. 9.2-16.I mu - region of homologous recombination. RSV - Rous sarcoma virus promoter. eGFP - green fluorescent protein. PA - Sv40 polyadenylation signal.

\section{Reporter expression in the murine liver}

The bifunctional adenovirus was delivered by direct hepatic injection into the liver of one day old wild-type mice $(\mathrm{N}=8)$. A total of $1.2 \times 10^{10}\left(3.3 \times 10^{8} \mathrm{PFU}\right)$ adenoviral particles were administered in a total volume of 10 microliters. Four days post injection the animals were sacrificed and the organs were inspected for fluorescence using a dissecting microscope equipped with a GFP filter. The GFP expression was easily visualized, with a higher concentration of signal seen in the lobe that was likely the direct target of injection (Figure 2A). The presence of green fluorescence, not observed in the uninjected mice, indicates that the RSV-eGFP promoter functioned in vivo. Other organs, such as the heart and kidney, lacked signal and GFP expression was not observed in the uninjected mice. None of the wild type mice injected at this dose perished, suggesting that the virus and procedure were well tolerated.

\section{Adenoviral correction of methylmalonyl-CoA mutase deficient murine embryonic fibroblasts (MEFs)}

Mut MEFs derived from methylmalonyl-CoA mutase knock-out mice were used to determine the efficacy of gene correction from the virus[24]. Methylmalonyl-CoA mutase protein and mRNA are not detectable in these cells (Figure 3 Lane 4; Chandler et al, submitted). The virus was incubated at a multiplicity of infection of 1000 for 16 hours. The cells were washed and then used to determine the extent of correction by Western blotting 72 hours post transduction. In parallel, enzymatic function was measured using macromolecular $\left[1-{ }^{14} \mathrm{C}\right]$ propionate incorporation. A wild-type murine fibroblast cell line served as a positive control in these experiments. Previous studies on the same cells using an E1 replaced, eGFP expressing adenovirus at the same MOI showed no effect on $\left[1-{ }^{14} \mathrm{C}\right]$ propionate incorporation and no gross cellular toxicity (Chandler et al, data not presented).
After correction, expression at the protein level was completely restored in the knock-out MEFs that had been infected. Figure 3A (Lane 4) shows that the Mut cells make no detectable methylmalonyl-CoA mutase protein compared to the wild type control (Lane 3), which has a single band migrating at $78 \mathrm{kDa}$. This band corresponds to the expected size of the murine enzyme after processing and is the same size as recombinant murine methylmalonylCoA mutase (Figure 3A, Lane 2). When normalized to actin, the enzymatic expression level in infected cells appears increased over wild type cells (compare Figure 3A Lane 5 to Lane 3).

We also measured the activity of the methylmalonyl-CoA mutase enzyme by evaluating propionate metabolism in Mut fibroblasts and compared it to Mut MEFs exposed to the virus. As demonstrated in Figure $3 \mathrm{~B}$, the $\left[1-{ }^{14} \mathrm{C}\right]$ propionate incorporation in the transduced cells nearly corrects to the levels observed in wild type cells, demonstrating that viral directed expression provides functional enzymatic correction.

\section{Adenoviral correction of methylmalonyl-CoA mutase deficient primary hepatocyte cell line}

The native liver from a patient with $m u t^{o}$ methylmalonic acidemia was harvested as part of a combined liver-kidney transplantation. Hepatocytes were isolated using collagenase perfusion. Cells were plated at a density of $5 \times 10^{5}$ per well on collagen-coated 6-well plates (Falcon) and appeared large, hexagonal and healthy. Control hepatocytes, derived from an 63 year old anonymous male donor, were prepared in an identical fashion and were used to measure native $[1-14 \mathrm{C}]$ propionate in an independent experiment.

The hepatocytes were infected at a MOI of 1000, as previously described. Twenty-four hours after infection the 
In vivo $(\mathrm{A})$ and in vitro $(\mathrm{B})$ delivery of GFP
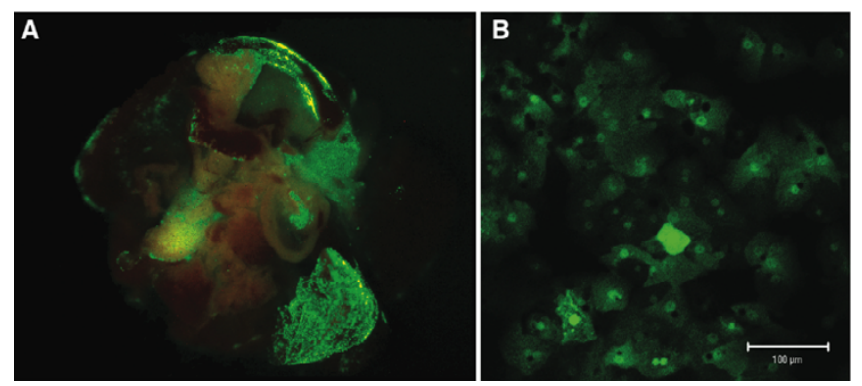

Figure 2

In vivo delivery of GFP to the murine liver and in vitro expression in primary mut $^{\circ}$ human hepatocytes. A. A wild-type neonatal mouse was treated on the first day of life by direct intrahepatic injection. The liver was harvested on the fourth day. The green-areas represent tissue that expresses eGFP. B. eGFP expression in primary mut ${ }^{\circ}$ human hepatocytes 24 hours after infection with the bi-functional adenovirus.

cells exhibited uniform GFP expression (Figure 2B). To access viral mediated correction, functional studies were performed on the hepatocytes with and without exposure to the adenovirus for $48 \mathrm{~h}$. Compared to a control human liver extract (Figure 4A, lane 1), extracts derived from the human $m u t^{\circ}$ liver (Figure 4A, lane 2) and uninfected hepatocytes (Figure 4A, lane 3 ) revealed no cross reactive material even after prolonged exposure of the Western blot. Genetic studies on this patient previously identified two nonsense mutations (E224X and R228X)[9] and these experiments confirmed that there was no read through. Post-infection, 10 micrograms of the mut $^{\circ}$ corrected hepatocyte extract exhibited a large increase in immunoreactive enzyme as assessed by Western blotting (Figure 4A, Lane 4). When compared to the control human liver extract (Figure 4A, Lane 1), which contained 20 micrograms of protein, the corrected cells (Figure 4A, Lane 4) have a substantially larger band, suggesting an increased capacity in the virally infected cells for expression of the methylmalonyl-CoA mutase enzyme, even if normalization to actin is not considered in the comparison.

Enzymatic studies revealed a greatly increased metabolic capacity of the mutant hepatocytes after viral correction (Figure $4 \mathrm{~B}$ ) $\left[{ }^{[1-14} \mathrm{C}\right]$ propionate incorporation in the virus exposed mut ${ }^{0}$ hepatocytes increased to approximately 20 $\mathrm{nmol} / \mathrm{mg} / 18 \mathrm{~h}$ (a factor of 7 ) over the uninfected cell line and exceeded the activity of control primary hepatocytes (Figure 4B). It should be noted that the control hepatocytes were derived from an older patient and hence may have a reduced propionate capacity compared with what might be observed in hepatocytes from a child, because of issues such as growth rate and/or other age related phe- nomenon. Unfortunately, an age and sex matched liver was not available for similar studies. The greatly increased $\left[1-{ }^{14} \mathrm{C}\right]$ propionate incorporation displayed by the $m u t^{o}$ cell line after viral correction indicates that hepatocytes have a large capacity for propionate metabolism and is consistent with the robust expression observed in the Western studies. In all the adenoviral delivery experiments, the infected cells appeared morphologically normal at the time enzymatic and Western studies were performed.

\section{Discussion}

In these studies, we developed and tested adenoviral gene delivery in murine Mut fibroblasts and human $m u t^{\circ}$ hepatocytes. The virus allowed the expression of a linked but distinctly transcribed cis eGFP minigene for rapid visual tracking of infectivity. After direct hepatic injection and incubation of primary human hepatocytes and MEFs (data not presented) with the virus, green fluorescence was readily apparent, demonstrating that the reporter functioned well in vivo and in vitro. Highly concentrated and purified virus allowed for small delivery volumes in vivo without adverse effects in the doses administered and was highly active in murine and human cell culture systems.

Murine, as opposed to human, Mut cDNA was selected for viral correction experiments because previous studies demonstrated the ability of the murine gene to correct human $m u t^{\circ}$ fibroblasts[30], despite the divergent sequence of its mitochondrial importation signal[31]. This is in contrast to other cross-species correction studies that have demonstrated the need for a species-specific mitochondrial importation signal[32]. Additionally, proof of principle studies using the mouse gene to correct murine mutant cells are needed before gene therapy experiments proceed in animal models of methymalonic acidemia. Retroviral delivery of the methylmalonyl-CoA mutase gene followed by selection has been used to correct a mutant methylmalonyl-CoA mutase deficient cell line but required multiple rounds of viral superinfection and selection to restore propionate metabolism[23]. Delivery with selection may represent an option suitable for retroviral or transposon mediated correction strategies but the rapidity of symptom onset in the Mut mice suggests that correction must be accomplished very early to be effective, possibly even in utero $[33,34]$. Adenoviral vectors can deliver a large dose of bioactive material quickly with highly efficient uptake and expression in the liver. The vector described here does not carry a selectable marker or provide permanent correction. Nevertheless, it may rescue neonatal Mut animals so that they can be studied at a later age. In this fashion, the treated mutants can serve as models for investigating the development of late, MMA-related pathophysiology such as basal ganglial inf- 


\section{A}

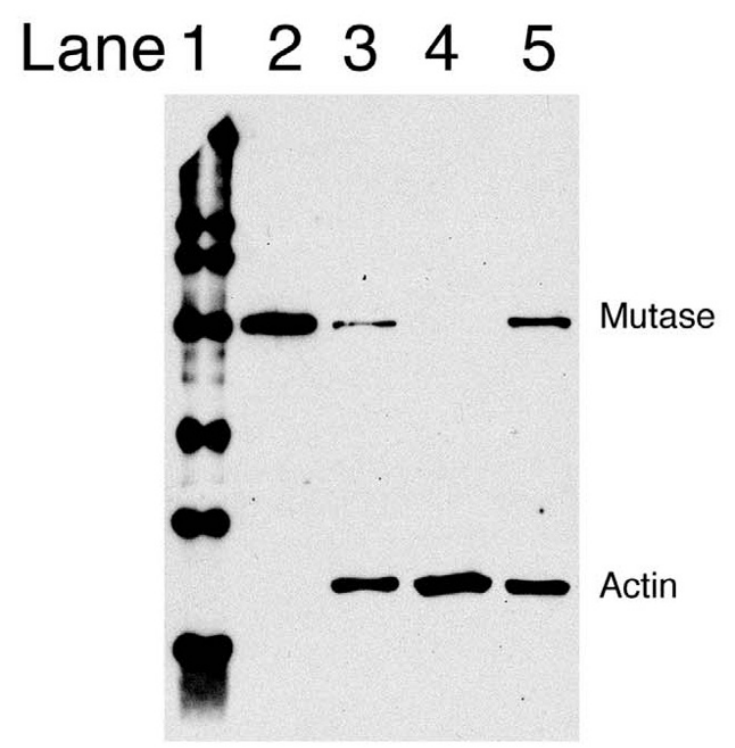

B

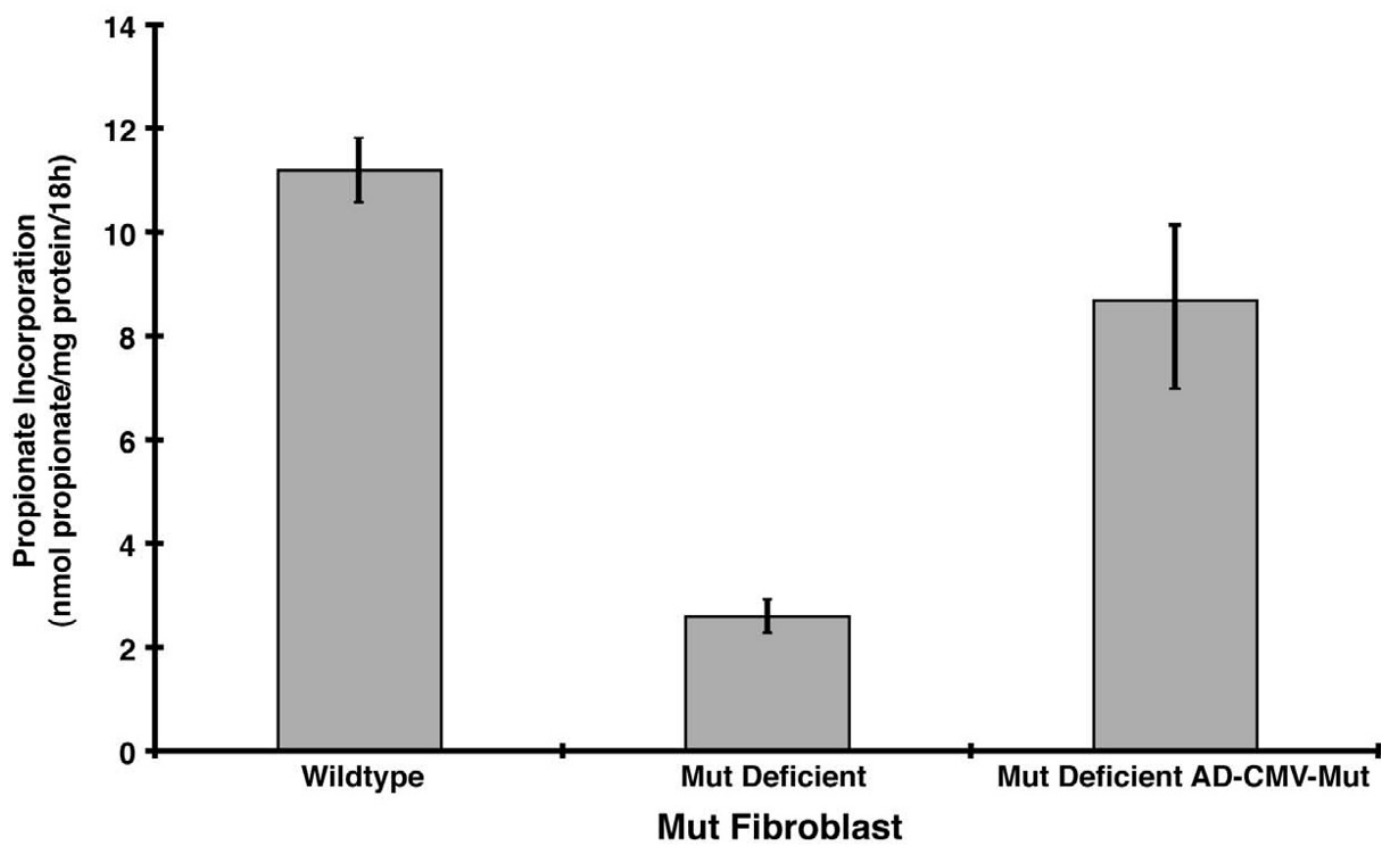

Figure 3

Expression and functional studies of methylmalonyl-CoA mutase in Mut murine embryonic fibroblasts. A. Western analysis of protein lysates from MEFs probed with methylmalonyl-CoA mutase antibody ( $78 \mathrm{kDa}$, labeled mutase) and cross-reactive betaactin loading control (47 kDa, labeled actin). All wells had 10 micrograms of total protein loaded. Lane I: Marker; Lane 2:

Recombinant murine methylmalonyl-CoA mutase; Lane 3: Wild-type MEF; Lane 4: Murine methylmalonyl-CoA mutase knockout MEFs; Lane 5: Adenoviral-corrected murine methylmalonyl-CoA mutase knock-out MEFs. B. Murine methylmalonyl-CoA mutase knock-out murine embryonic fibroblasts (uncorrected and corrected with adenovirus) were assayed for $\left[1-{ }^{14} \mathrm{C}\right]$ propionate incorporation over 18 hours. Activity was normalized to total protein content of the extracts. The samples were analyzed in triplicate. The bars around the average represent $+/$ - one standard deviation. 
A

Lane $11 \quad 2 \quad 3 \quad 4$

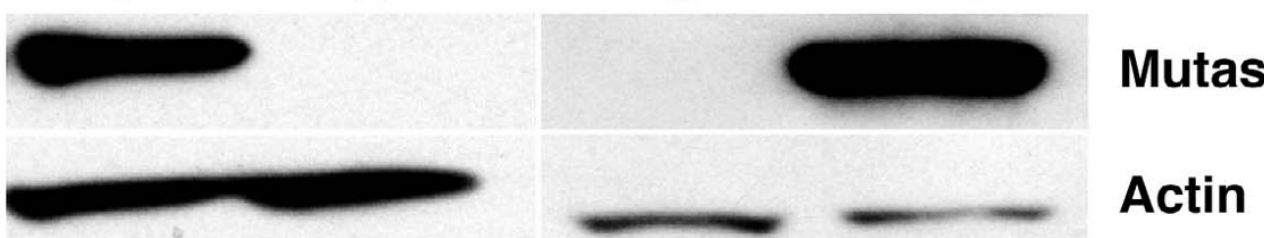

B

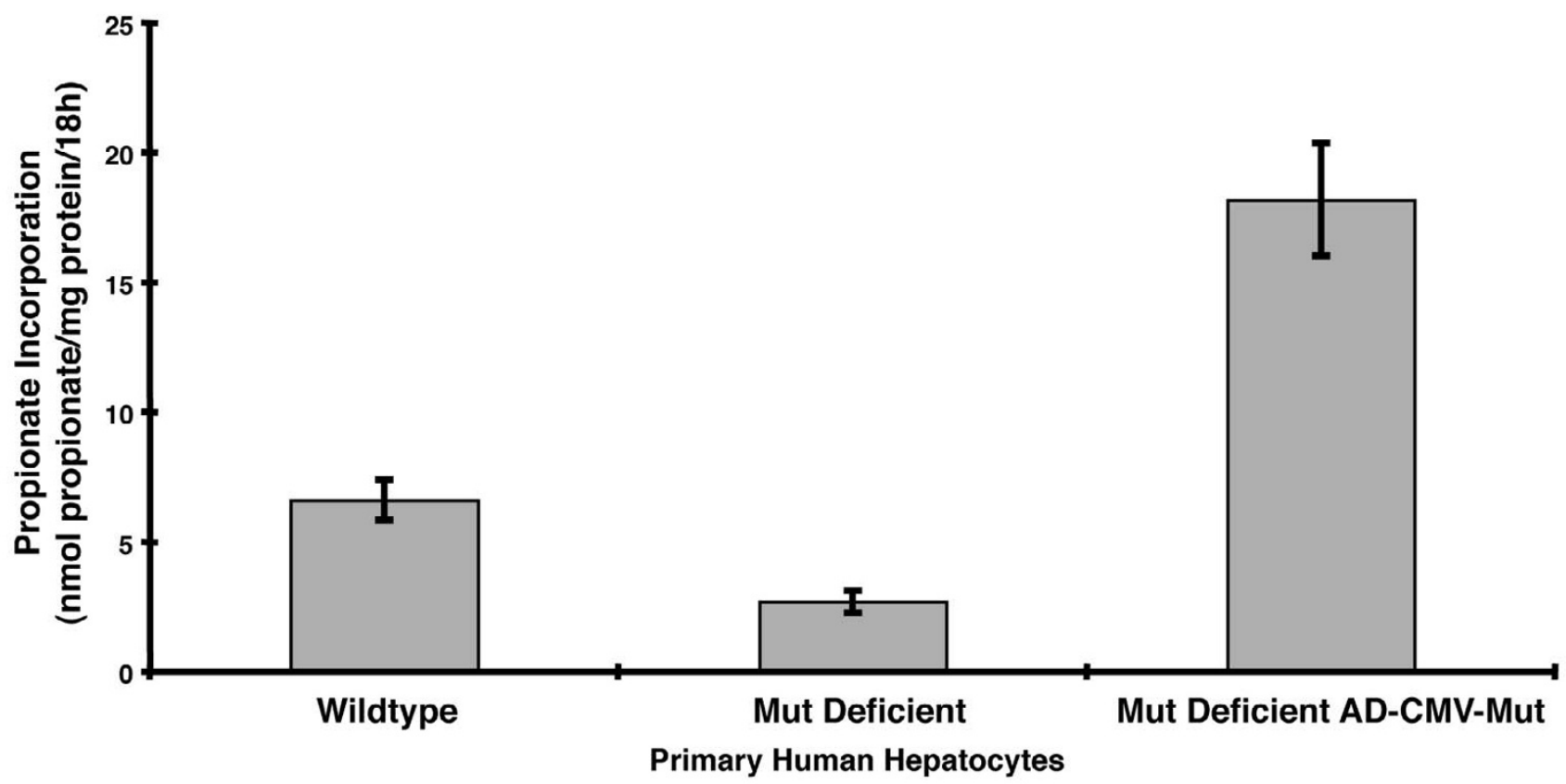

\section{Figure 4}

Expression and functional studies of methylmalonyl-CoA mutase in primary mut ${ }^{\circ}$ human hepatocytes. A. Western analysis of protein lysates from primary human hepatocytes probed with methylmalonyl-CoA mutase antibody (78 kDa, labeled mutase) and cross-reactive beta-actin loading control (47 kDa, labeled actin). Lane I: human control whole liver extract (20 micrograms) Lane 2: mut $^{\circ}$ whole liver extract (20 micrograms); Lane 3: human primary mut ${ }^{\circ}$ primary human hepatocytes ( 10 micrograms); Lane 4: adenoviral corrected mut ${ }^{\circ}$ primary human hepatocytes ( 10 micrograms). B. Human hepatocytes (wild type, mut ${ }^{\circ}$ and mut $^{\circ}$ corrected with adenovirus) were assayed for $[1-14 \mathrm{C}]$-propionate incorporation over 18 hours after viral incubation for $48 \mathrm{hrs}$. Activity was normalized to total protein content of the extracts. The samples were analyzed in triplicate. The bars around the average represent $+/$ - one standard deviation. 
arction, pancreatitis and renal disease and also be used to assess other cell and viral based therapies.

In these studies, adenoviral correction of primary human $m u t^{o}$ heptocytes was especially effective. Other authors have demonstrated that hepatocytes possess an increased basal capacity for propionate metabolism[23,35] as our results also suggest. Furthermore, when individual murine tissues were examined for methylmalonyl-CoA mutase activity, the liver possessed a large amount of active enzyme, with an total activity of $>1400 \mathrm{nmol}$ succinate formed/h per mg of protein[31]. Taken together with the observations that mut liver transplant recipients are quite stable despite having massive methymalonic acidemia[20,36,37], the concept of targeting the liver for gene delivery appears attractive.

Our results show that adenoviral mediated gene delivery can greatly increase propionate metabolism in mutant hepatocytes. The genetic background of the Mut murine MEFs and human $m u t^{\circ}$ hepatocytes is similar because both are null at the protein level as confirmed by Western analysis (Figures 3 and 4). Although many affected mut patients harbor missense mutations $[8,9]$ and interallelic effects are a well recognized phenomenon[38], the extent of correction we achieved is likely to be influenced only by gene expression from the viral cassette, not partial rescue or stabilization of a mutant protein due to the nature of the nonsense mutations present in the patient.

Liver transplantation has been used to augment medical therapy for both methylmalonic[39] and propionic acidemia[40]. Affected individuals can have mild steatosis and transaminitis but maintain normal synthetic liver function[2]. However, when these patients have undergone hepatic transplantation, the native livers have not been used in a domino fashion, as has been done in other metabolic disorders of branched chain aminoacid oxidation, such as maple syrup urine disease[41]. Most methymalonic acidemia patients undergoing liver transplantation will have the organ harvested and discarded or sent to pathology. We have demonstrated that an otherwise functionless liver can be used for scientific studies that have relevance to hepatocyte therapy and gene delivery and suggest that, in the future, the disposition of harvested organs from methylmalonic acidemia and other patients be carefully considered. Mutant human hepatocytes isolated from otherwise unusable donor livers, particularly those affected by metabolic disorders, might also be used to create hepato-specific genetic mosaic animals by transplantation approaches[42]. This approach would allow the in vivo propagation of affected human cells in mice and might permit experiments not possible in either species. Future efforts will focus on adenoviral mediated gene delivery to rescue the neonatal lethal phenotype seen in Mut knock-out mice, an approach that now has firm experimental evidence of efficacy.

\section{Conclusion}

Our results demonstrate, for the first time, efficacious viral mediated gene correction in primary murine and human methylmalonyl-CoA mutase deficient cell lines. Primary hepatocytes derived from an affected patients liver that was unsuitable for transplantation provided an important resource for these studies. In the future, hepatocytedirected gene therapy should provide an effective therapeutic treatment in both murine models and in human patients.

\section{Abbreviations}

MMA (methylmalonic acidemia), MUT (human methylmalonyl-CoA mutase), Mut (murine methylmalonyl-CoA mutase), mut $^{\circ}$ (vitamin B12 non-responsive methylmalonic acidemia), MEF (murine embryonic fibroblasts), MOI (multiplicity of infection), PFU (plaque forming units), CMV (cytomegalovirus), RSV (Rous sarcoma virus), eGFP (enhanced green fluorescent protein)

\section{Competing interests}

The author(s) declare that they have no competing interests.

\section{Authors' contributions}

RJC performed viral, murine, and biochemical studies and drafted the manuscript; MST performed viral, murine, and biochemical studies; KD isolated hepatocytes; SS provided research materials and aided with manuscript revision; JS provided patient care, clinical information and aided with manuscript revision, $\mathrm{MK}$ and RF provided patient care, clinical information and procured samples; and CPV constructed the adenoviral vector and was responsible for the concept of the study, its design and coordination and drafted the manuscript. All authors read an approved the final manuscript.

\section{Acknowledgements}

Organ donations by patients and patient's families were critical to these studies and are gratefully acknowledged. MT received funding from the Organic Acid Association-MMA Research Fund; RC, JS and CPV were supported, in part, by the Intramural Research Program of the National Human Genome Research Institute, National Institutes of Health. SS and KD were supported in part by NIH/NIDDK DK-9-2310, the Liver Tissue Procurement and Distribution System.

\section{References}

I. Fenton WA, Gravel RA, Rosenblatt DS: Disorders of Propionate and Methylmalonate Metabolism in The Metabolic and Molecular Bases for Inhertited Disease. 8th edition. Edited by: Scriver CR, Beaudet AL, Sly WS, Valle D. McGraw-Hill, Inc., New York; 2001:2165-2192. 
2. Oberholzer VG, Levin B, Burgess EA, Young WF: Methylmalonic aciduria. An inborn error of metabolism leading to chronic metabolic acidosis. Arch Dis Child 1967, 42:492-504.

3. Stokke O, Eldjarn L, Norum KR, Steen-Johnsen J, Halovorsen S: Methylmalonic acidemia: A newborn error of metabolism which may cause fatal acidosis in the neonatal period. Scand J Clin Lab Invest 1967, 20:3 |3-328.

4. Matsui SM, Mahoney MJ, Rosenberg LE: The natural history of the inherited methylmalonic acidemias. $N$ Engl J Med 1983, 308:857-86I.

5. van der Meer SB, Poggi F, Spada M, Bonnefont JP, Ogier H, Hubert P, Depondt E, Rapoport D, Rabier D, Charpentier C, et al: Clinical outcome of long-term management of patients with vitamin B I2-unresponsive methylmalonic acidemia. J Pediatr 1994, I 25:903-908.

6. Nicolaides P, Leonard J, Surtees R: Neurological outcome of methylmalonic acidaemia. Arch Dis Child 1998, 78:508-5I 2.

7. de Baulny HO, Benoist JF, Rigal O, Touati G, Rabier D, Saudubray JM: Methylmalonic and propionic acidaemias: management and outcome. J Inherit Metab Dis 2005, 28:4I5-423.

8. Acquaviva C, Benoist JF, Pereira S, Callebaut I, Koskas T, Porquet D, Elion J: Molecular basis of methylmalonyl-CoA mutase apoenzyme defect in $\mathbf{4 0}$ European patients affected by mut(o) and mut-forms of methylmalonic acidemia: identification of $\mathbf{2 9}$ novel mutations in the MUT gene. Hum Mutat 2005 , 25:167-176.

9. Worgan LC, Niles K, Tirone JC, Hofmann A, Verner A, Sammak A, Kucic T, Lepage P, Rosenblatt DS: Spectrum of mutations in mut methylmalonic acidemia and identification of a common Hispanic mutation and haplotype. Hum Mutat 2006, 27:3 I-43.

10. Fenton WA, Hack AM, Kraus JP, Rosenberg LE: Immunochemical studies of fibroblasts from patients with methylmalonyl-CoA mutase apoenzyme deficiency: detection of a mutation interfering with mitochondrial import. Proc Natl Acad Sci USA 1987, 84:|42|-|424.

II. Janata J, Kogekar N, Fenton WA: Expression and kinetic characterization of methylmalonyl-CoA mutase from patients with the mut-phenotype: evidence for naturally occurring interallelic complementation. Hum Mol Genet 1997, 6: | 457-| 464.

12. Crane AM, Ledley FD: Clustering of mutations in methylmalonyl CoA mutase associated with mut-methylmalonic acidemia. Am J Hum Genet 1994, 55:42-50.

13. Kahler SG, Sherwood WG, Woolf D, Lawless ST, Zaritsky A, Bonham J, Taylor CJ, Clarke JT, Durie P, Leonard JV: Pancreatitis in patients with organic acidemias. J Pediatr 1994, 1 24:239-243.

14. Heidenreich R, Natowicz M, Hainline BE, Berman P, Kelley RI, Hillman RE, Berry GT: Acute extrapyramidal syndrome in methylmalonic acidemia: "metabolic stroke" involving the globus pallidus. J Pediatr 1988, I I 3:1022-1027.

15. Korf B, Wallman JK, Levy HL: Bilateral lucency of the globus pallidus complicating methylmalonic acidemia. Ann Neurol 1986, 20:364-366.

16. Baumgarter ER, Viardot C: Long-term follow-up of 77 patients with isolated methylmalonic acidaemia. J Inherit Metab Dis 1995, I 8: I 38-142.

17. Roe CR, Hoppel CL, Stacey TE, Chalmers RA, Tracey BM, Millington DS: Metabolic response to carnitine in methylmalonic aciduria. An effective strategy for elimination of propionyl groups. Arch Dis Child 1983, 58:916-920.

18. van 't Hoff WG, Dixon M, Taylor J, Mistry P, Rolles K, Rees L, Leonard $\mathrm{JV}$ : Combined liver-kidney transplantation in methylmalonic acidemia. J Pediatr 1998, I 32: 1043-1044.

19. Kayler LK, Merion RM, Lee S, Sung RS, Punch JD, Rudich SM, Turcotte JG, Campbell DA Jr, Holmes R, Magee JC: Long-term survival after liver transplantation in children with metabolic disorders. Pediatr Transplant 2002, 6:295-300.

20. Nyhan WL, Gargus J], Boyle K, Selby R, Koch R: Progressive neurologic disability in methylmalonic acidemia despite transplantation of the liver. Eur J Pediatr 2002, I 6 I:377-379.

21. Chakrapani A, Sivakumar P, McKiernan PJ, Leonard JV: Metabolic stroke in methylmalonic acidemia five years after liver transplantation. J Pediatr 2002, I 40:26I-263.

22. Strom SC, Bruzzone P, Cai H, Ellis E, Lehmann T, Mitamura K, Miki T: Hepatocyte transplantation: clinical experience and potential for future use. Cell Transplant 2006, I5(SuppI I):SI05-IIO.
23. Sawada T, Ledley FD: Correction of methylmalonyl-CoA mutase deficiency in Mut0 fibroblasts and constitution of gene expression in primary human hepatocytes by retroviral-mediated gene transfer. Somat Cell Mol Genet 1992, I 8:507-5 I6.

24. Venditti CCR, Tsai M, Wehrli N, Deering R, Kaestner K, Gaiver G, Kazazian H: Genetic and Genomic Systems to Study Methylmalonic Acidemia (MMA). Mol Genet Metab 2005, 84:207-208.

25. Chandler RJ, Aswani V, Tsai MS, Falk M, Wehrli N, Stabler S, Allen R, Sedensky M, Kazazian HH, Venditti CP: Propionyl-CoA and adenosylcobalamin metabolism in Caenorhabditis elegans: evidence for a role of methylmalonyl-CoA epimerase in intermediary metabolism. Mol Genet Metab 2006, 89:64-73.

26. Kostrubsky VE, Ramachandran V, Venkataramanan R, Dorko K, Esplen JE, Zhang S, Sinclair JF, Wrighton SA, Strom SC: The use of human hepatocyte cultures to study the induction of cytochrome P-450. Drug Metab Dispos 1999, 27:887-894.

27. Strom SC, Pisarov LA, Dorko K, Thompson MT, Schuetz JD, Schuetz EG: Use of human hepatocytes to study $\mathbf{P} 450$ gene induction. Methods Enzymol 1996, 272:388-40I.

28. Anderson RD, Haskell RE, Xia H, Roessler BJ, Davidson BL: A simple method for the rapid generation of recombinant adenovirus vectors. Gene Ther 2000, 7:1034-1038.

29. Willard HF, Ambani LM, Hart AC, Mahoney MJ, Rosenberg LE: Rapid prenatal and postnatal detection of inborn errors of propionate, methylmalonate, and cobalamin metabolism: a sensitive assay using cultured cells. Hum Genet 1976, 34:277-283.

30. Wilkemeyer MF, Crane AM, Ledley FD: Differential diagnosis of mut and cbl methylmalonic aciduria by DNA-mediated gene transfer in primary fibroblasts. J Clin Invest 1991, 87:915-918.

31. Wilkemeyer MF, Crane AM, Ledley FD: Primary structure and activity of mouse methylmalonyl-CoA mutase. Biochem J 1990, 27 I:449-455.

32. Ye X, Zimmer KP, Brown R, Pabin C, Batshaw ML, Wilson JM, Robinson $M B$ : Differences in the human and mouse amino-terminal leader peptides of ornithine transcarbamylase affect mitochondrial import and efficacy of adenoviral vectors. Hum Gene Ther 2001, I 2: 1035-1046.

33. Peters H, Nefedov M, Sarsero J, Pitt J, Fowler KJ, Gazeas S, Kahler SG, loannou PA: A knock-out mouse model for methylmalonic aciduria resulting in neonatal lethality. J Biol Chem 2003, 278:52909-52913.

34. Chandler RJ, Venditti CP: Genetic and genomic systems to study methylmalonic acidemia. Mol Genet Metab 2005, 86:34-43.

35. Wilkemeyer M, Stankovics J, Foy T, Ledley FD: Propionate metabolism in cultured human cells after overexpression of recombinant methylmalonyl CoA mutase: implications for somatic gene therapy. Somat Cell Mol Genet 1992, I 8:493-505

36. Nagarajan S, Enns GM, Millan MT, Winter S, Sarwal MM: Management of methylmalonic acidaemia by combined liver-kidney transplantation. J Inherit Metab Dis 2005, 28:5 I7-524.

37. Kaplan P, Ficicioglu C, Mazur AT, Palmieri MJ, Berry GT: Liver transplantation is not curative for methylmalonic acidopathy caused by methylmalonyl-CoA mutase deficiency. Mol Genet Metab 2006, 88:322-326.

38. Raff ML, Crane AM, Jansen R, Ledley FD, Rosenblatt DS: Genetic characterization of a MUT locus mutation discriminating heterogeneity in muto and mut-methylmalonic aciduria by interallelic complementation. J Clin Invest I991, 87:203-207.

39. Kasahara M, Horikawa R, Tagawa M, Uemoto S, Yokoyama S, Shibata Y, Kawano T, Kuroda T, Honna T, Tanaka K, Saeki M: Current role of liver transplantation for methylmalonic acidemia: a review of the literature. Pediatr Transplant 2006, 10:943-947.

40. Barshes NR, Vanatta JM, Patel AJ, Carter BA, O'Mahony CA, Karpen SJ, Goss JA: Evaluation and management of patients with propionic acidemia undergoing liver transplantation: a comprehensive review. Pediatr Transplant 2006, I0:773-78I.

4I. Khanna A, Hart M, Nyhan WL, Hassanein T, Panyard-Davis J, Barshop BA: Domino liver transplantation in maple syrup urine disease. Liver Transpl 2006, I 2:876-882.

42. Grompe M: Principles of therapeutic liver repopulation. J Inherit Metab Dis 2006, 29:421-425. 


\section{Pre-publication history}

The pre-publication history for this paper can be accessed here:

http://www.biomedcentral.com/1471-2350/8/24/prepub

Publish with Bio Med Central and every scientist can read your work free of charge

"BioMed Central will be the most significant development for disseminating the results of biomedical research in our lifetime. " Sir Paul Nurse, Cancer Research UK

Your research papers will be:

- available free of charge to the entire biomedical community

- peer reviewed and published immediately upon acceptance

- cited in PubMed and archived on PubMed Central

- yours - you keep the copyright 